\title{
Adapting Herzberg's Motivation-Hygiene Theory to a VUCA World - A Repertory Grid Study
}

\section{Henning Bundtzen}

Szent István University, Faculty of Economic Science, Kaposvár, Hungary

\begin{abstract}
Employee motivation is a key driver of organizational performance and employee retention. An increasing shortage of skilled workers forces companies to think of ways to motivate and retain their employees. Herzberg's two-factor theory of motivation provides an insight which factors are relevant for motivating employees. The theory founded on research carried out in the 1960's. Since then, the practical and theoretical tenet of supervision and management has shifted to a different leadership approach. Additive the economic environment is found to be more volatile, unpredictable, complex and ambiguity. VUCA has made its way into organizational science resulting in a focus on agile working methodologies. To add up a generation of millennials demanding for feedback, open communication and teambased workplaces starts to integrate into labour market. Does Herzberg's theory persist in this new economic environment? Can it be adapted or is a completely new approach inevitable? This organizational psychology related study is aimed to test Herzberg's theory in a contemporary environment by applying the theory of personal constructs as an investigative method. 61 qualitative repertory grid structured interviews elicited $n=782$ personal constructs to investigate the theory. The personal constructs are clustered and compared to the theory of Herzberg.
\end{abstract}

Keywords: Employee motivation theories, Two factor theory, repertory grid analysis, theory of personal constructs, organizational performance, organizational psychology, employee retention

\section{Introduction}

Human motivation has been a key interest in research for many centuries. Maslow and McCelland focused in their theories on the individual to explain differences in motivation. Herzberg approached the topic from an organizational perspective as he concentrated on the job itself and work activities, their influence on an employee's motivation and performance (Steers et al. 2004). Herzberg initially reviewed the existing research in that area to establish a survey of 200 accountants and engineers. From this research his initial framework about job design including his theory of motivation was founded (Herzberg et al. 1959). Since the motivation-hygiene theory had an influential impact to the scientific as well as practical notion. The factors described in his theory can be influenced by an organization to make jobs intrinsically challenging and provide opportunities for recognition (Steers et al. 2004). Herzberg explained motivation by dividing the topic into two different types of factors (Herzberg et al. 1959). He concluded that job satisfaction and dissatisfaction were two 
distinguishable dimensions of work related values of growth needs and lower-order needs (Knoop 1994). Firstly, hygiene factors that do not increase motivation but lead to dissatisfaction if they are not prearranged in an organisation. The hygiene factors are company policy, supervision, salary, relationship with peers, status and security (Herzberg et al. 1959). The satisfaction characteristic of hygiene factors refers more to the gratification of needs and wants of an employee and have an extrinsic character (Knoop 1994). Several interconnected theories of job satisfaction try to analyse the process and the content of work values and satisfaction (Locke 1969). Even the motivator-hygiene theory was criticized repeatedly it still leads to a distinction between job satisfaction and work motivation in future research (Knoop 1994; Ewen et al. 1966). Further research found that the above-mentioned factors are likewise a key driver for employee retention which is inconsistent to the original hygienemotivation theory by Herzberg (Tamosaitis und Schwenker 2002).

Secondly the motivation factors are of an intrinsic nature. They result in more motivation if put into practice by an organization. As motivational factors Herzberg listed achievement, recognition, work itself and responsibility (Herzberg 1966; Herzberg et al. 1959). Further research done by Lawler supported the theory as he found that satisfaction indicates an employee's motivation to come to work but only indirectly influences the motivation for doing the job effectively (Lawler 1969). Semerek and Peterson concluded in their study on the motivation-hygiene theory that only work itself acts in accordance to Herzberg's theory as they evaluated the impact on job satisfaction (Smerek und Peterson 2006). Thus, Herzberg determined that jobs should be designed to challenge workers with responsibility, while giving them opportunities for advancement. This would result in personal growth and is fostered by recognition (Hackman, J. R., \& Oldham, G. R. 1976). They have extended the research as it relates to work design, motivation, and job performance. The consequences of Herzberg's framework for leadership behaviour were studied by Arnold et al. (2000) who identified eight essential leadership traits necessary in empowerment: Leading by example, Coaching (education of team members), encouraging, participative decision making, informing, showing concern for members well-being, interacting with the team and group management. This approach to leadership is different to the dominant concept of supervision and management when Herzberg wrote his theory. Already in 1979 Orpen found in his research evidence of Heckman-Oldham's theory on job design. Managers should not focus on giving employees tasks of similar challenge or responsibility (horizontal loading) but instead transfer tasks that loads them vertically with handing over more responsibility for example. This increases the role of a manager from motivating employees only by compensation, good working conditions and similar factors to real motivation of their workers. The outcome is an increase in motivation but not necessarily a greater productivity according to Orpen's (1979) research.

Controversial of Herzberg, Mausner and Snydermans initial research is that they left the interpretation open in their conclusion (King 1970). Consequently, different versions of the theory were identified while no version was supported by two or more methods of testing nor validating (King 1970; Gardner 1977, 1977). Another criticism arises from peoples' tendency to socially desirable answers which results in an attribution of external factors towards impacting dissatisfaction (Wall und Stephenson 1970). The intuitive approach used in repertory grid structured interviews based on Kelly's personal construct theory has proven to eliminate this effect (Hauser et al. 2011). Other studies that used a different method than the original research were contradictive to Herzberg's findings. A clear line between hygiene 
and motivating factors was not given for example in the research of Brenner et al. or Maidani (Brenner et al. 1971; Maidani 1991). Nevertheless, Brenner also stated that the wording of the questions, the method of presenting the questions etc. have an impact on the results of a study (Brenner et al. 1971). This makes a completely new approach to testing the theory in today's work environment so worthwhile and was the reason for this study.

To a similar degree to which critical studies about Herzberg's theory are published it is possible to find research that supports the evidence provided by the hygiene-motivation theory. Sachau for example suggests a resurrecting of the motivation-hygiene theory as it has strong correlations to research on intrinsic motivation and positive psychology (Sachau 2007). Looking at the term itself in literature and similarly in practice the term responsibility has been broadened by the concept of empowerment. Chen et al. conceptualize this term by including impact, competence, meaningfulness and choice while distinguishing between individuals and teams (Chen et al. 2007). The effect of team composition has not been addressed by Herzberg's theory which would widen the approach. Especially as teamwork has increased in significance since his theory due to the change in values and norm of the generations after the baby boomers. Empirical research highlighted three traits of millennials in relation to their interactions and relationship at work. Firstly, they prefer a team-based workplace culture which compromises close contact and communication with supervisors (Stewart et al. 2017; Costanza et al. 2012). This should in return influence their motivation factors. In addition, frequent feedback is requested from a managerial perspective. Performance appraisal though is asked to be based on contributions to an organizational objective and strategic goals instead of specific traits of an employee (Myers und Sadaghiani 2010). Costanza et al. (2012) found in their meta-analysis both a difference in job satisfaction and job turnover between distinct generations. In terms of motivation Wong et al. (2008) highlighted that power and authority has decreased in importance as motivational driver from generation to generation.

An investigation of the relationship between work values and job satisfaction compiled by Knoop (1994) clustered Herzberg's two factor theory into five sets of values: intrinsic workrelated, intrinsic work-outcome, extrinsic job-related, extrinsic job-outcome and extrinsic people related. His research aimed to identify the best predictors of job satisfaction for these five sets of values. Other studies have revealed that increased job satisfaction is important by most workers. A contrary picture can be drawn when workers are requested to rank the importance of increasing job satisfaction against other types of employment goals which are relevant to them (Caston, R. J., \& Braito, R. 1985). This resulted in about 50\% of employees rating job satisfaction in the bottom half of the scale ranks. Summarized Caston, R. J., \& Braito, R. (1985) found empirical evidence relevant to the two-factory theory by Herzberg. Their theory suggests that intrinsic factors contribute to job satisfaction which is not the case for extrinsic factors. Caston and Braito (1985) added the variable of "workers-to-job fit" to the motivator-hygiene theory to explain differences in job satisfaction.

Based on the two-factor theory Locke and Latham (1990) construed a performance cycle as high motivation alone does not necessarily result in continuous high performance. In addition, moderating factors, namely goal commitment, feedback, ability, task complexity and situations constrains have an impact on the performance results (Locke und Latham 1990). This performance cycle started to integrate preferences of millennials into the motivation framework. 
Finally, it remains open how the increased volatility, uncertainty, complexity and ambiguity (VUCA) of the economic environment which made agile and flexible management methods like Scrum, Kanban and lean indispensable (Baran und Woznyj 2020) effects Herzberg's framework. A review of search results on ScienceDirect by the Elsevier publishing house makes evident that agile working methods have increased in importance every year. While in the early 2000's the search term "agile organization" produces only 200 - 300 results this increased to 1,000 - 2,270 since 2014 to 2019. An adapted two-factor framework should certainly integrate this economic development. Questionable is whether it fits as a hygiene or motivation factor into the framework.

\section{Hypotheses}

From the literature review the following hypotheses were concluded. The first picks up the criticism that the questionnaire pointed the enquired people towards the results of Herzberg's theory by the design of the questionnaire. This, especially with the elements chosen in this investigation is equalled out by a repertory grid study as there is not direct link to motivator or hygiene factors. In case Herzberg's theory holds valid today, we would expect these factors to still be part of the elicited constructs of this study:

$H_{1}$ : The repertory grid approach still creates construct clusters referable to the factors stated in Herzberg's theory.

Leadership has passed through several stages in the past decades. Whilst an autocratic leadership style with clear instructions on what and how work must be carried out was still accepted and considered a hygiene factor, this has changed considerably. According to contemporary research on leadership and motivation the role of leaders has changed into something like a coach with a cooperative leadership style. Hence, we would expect to find evidence in the data set that the "quality of supervision" or leadership has changed into a motivational factor instead of a hygiene factor.

$\mathrm{H}_{2}$ : Leadership and quality of supervision has become a motivational factor.

Not only the generation changes in workforce but also the economic environmental changes may have an impact on organizational culture. The VUCA world is an influential driver of organizational performance (Bennett und Lemoine 2014). Deductive it influences employee's motivation likewise. This leads to the hypothesis that as a response to the VUCA world agile working methods and an open-minded approach for new ideas by leaders is a necessity resulting in a hygiene factor.

$\mathrm{H}_{3}$ : Agile working methods can by identified as a hygiene factor.

The value and norms of millennials in the work environment have caused an integration of team-based workplace culture and feedback as a motivational.

$H_{4}$ : Teamwork and feedback can be identified as motivational factors.

\section{Materials and Methods}

This qualitative research employs an inductive approach to study employee's hygiene and motivation factors in a work environment. A reunion of Herzberg's two factor theory with Kelly's (1955) personal construct psychology (PCP) supplied a theoretical method. Kelly (1955) indicated in his theory that people continuously attempt to make sense of their own 
humankind and their place within the world surrounding them (Cassell et al. 2000). This is done by placing experiences and events in relation to each other in various circumstances (Fromm 2004). In this research the theory is employed to an organization surrounding an individual. Therefore, an originally psychological theory is exploited to evaluate how employees see their employer in this case focused on hygiene and motivational factors. This method makes the subjective and personal worlds of workers within an organization visible. The repertory grid technique used in this study is an unbiased qualitative and quantitative method (Robertson 2004) to evaluate the motivational status quo of an organization and if Herzberg's theory is reflected somehow. The methodology is not a psychometric test but repertory grid interviews are rather a structured consultation technique that grounds on PCP (Fromm 2004). It works on comparisons between in this context organizational elements. The interviewees expressions to differentiate these elements are logged in a data matrix (Scheer und Catina 1993). The findings correspond to the subjective reality of the interviewed person in an idiographic way (Bourne und Jankowicz 2018). As a basis for this research 61 repertory grid structured interviews (all 21 managers and 40 employees in proportion of the size of each department) were carried out within an organization. The research object is a wholesale company in the consumer industry with approximately 500 employees of which 21 staff members are in leadership roles. The software rep:grid (by sofistiq) was employed for collection and analysis of the data. The tool enables several interview settings. For this study, the comparison method triad oppositional was used. Consequently, probands were presented three different elements to elicit their constructs. The evaluation method was conducted in a tetrapolar field. The web based tool generates the results after completing the interview to enable consensual validity of the elicited results (Lohaus 1983). The main objective of this research is to analyse whether Herzberg's motivation-hygiene theory can be verified by appliance of Kelly's theory of personal constructs as a research model. Each computer supported face-to-face interview lasted 120 minutes and generated an average of 13 personal constructs per interview, in total 782.

The determination of elements must adhere to some basic guidelines to guarantee a complete coverage of the research issues. The main principles for selecting elements are that they are consistent in the meaning that they represent the same category. Additionally, elements should be representative to the subject explored and explicit to the interviewee (EasterbySmith et al. 1996). Wright and Lam propose supplementary heterogeneous elements that indicate a profound interpretation of the researched topic (Wright und Lam 2002). The following 27 elements were employed to represent the company and are designed to elicit motivation related constructs:

All elements

The organization \& market

The company as it used to be

The company today

The company in 2.5 years

The ideal company

A negative company
Leadership \& Motivation

Myself today

My direct manager

The company without leadership

Ideal leadership

Leadership culture
Quality and internal processes

$H R$

Logistics/Warehouse

Sales Department

Product management / purchase

IT 


$\begin{array}{lll}\text { The companies brand } & \text { Myself as a manager } & \text { Marketing } \\ \text { The market in the future } & \text { CEO } 1 & \text { Employee culture } \\ \text { An unpleasant competitor } & \text { CEO } 2 & \text { Quality principle } \\ \text { A meaningful company } & \text { A highly motivated person } & \text { An efficient process }\end{array}$

Table 1: All 27 applied elements

The 27 elements are grouped into 3 main area. Evidently that the second cluster of leadership and motivation includes the elements for this research. The element "A highly motivated person" is selected to explicitly trigger motivation related constructs without directly asking questions. This is one of criticized issues of Herzberg's original research (Brenner et al. 1971, 1971; Gardner 1977, 1977). The inductive approach of repertory grids still allows the interviewees to state motivation related constructs whilst not bringing up thoughts that they do not use in the context of judging the organization they are working for.

The procedure of repertory grid structured interviews can be divided into three phases:

Interviewees compare a triad of three elements of the set of 27 to elicit their personal constructs. While faced with three elements they are asked, "in what way are two of these elements similar to each other and different from the third one". As the elements are related to motivation contextual constructs are elicited.

Afterwards the probands state a contrary to their initially construed construct. The assessment method selected is "triad oppositional" (Easterby-Smith et al. 1996) meaning that a tetrapolar field is used for evaluating the elements. This enables a diverse set of possible assessments (Senior und Swailes 2004).

In phase three the interviewees rate all 27 elements in the tetrapolar field in dependence of their created construct poles. This process was reiterated until no additional constructs were produced.

Elements like "a highly motivated person" or "an efficient process" assist creative reasoning to ideally elicit a distinct quantity of qualitatively distinguishable images that define the corporate culture in close association with motivational factors.

The selection of these elements intended to translate Herzberg's theory into personal constructs that show how employees evaluate and judge the elements that are presented to them (Kelly 2002). Consequently, interviewees do not answer to questions and factors that they before did not have in mind, a main criticism of Herzberg's investigation methodology. As motivation is closely related to leadership several elements were chosen which provoke experiences and thoughts about this topic.

The collected data was evaluated with a specialized software that uses Generalized Procrustes Analysis (GPA) to define the unique coordinates of each construct and element. GPA enables to analysis and visualization of three-dimensional data matrices (Mak et al. 2013). The analysis reveals how constructs are grouped together and in which mathematical context they stand to each other (Grice und Assad 2009). The selection of the above-mentioned elements does not allow to predict any derived constructs, but the context determines that topic related constructs are created (Fransella 2004). The explanation of the matrix focuses on the creation of construct clusters with a similar meaning (Hauser et al. 2011). In addition, the location of 
elements in combination with construct clusters allows comprehension of the perceived company culture of the interviewees. The GPA was carried out in three dimensions to ensure practicability and facilitate descriptive qualitative analysis with results presented in threedimensional plots.

An analysis of the results requires a common understanding of the spatial representation demonstrated in three-dimensional graphics of this study. The distances between clusters of constructs and elements and their allocation in the grid are quantitative figures which allow in their interplay a qualitative analysis of the data set (Hauser et al. 2011). In case the coordinates of constructs and elements represent a small special distance, this means they are rated similar by probands. Elements and clusters each have a certain set of coordinates which enables to measure the distances as a percentage of 100. As an example, "The ideal company" and "Ideal Leadership" have a very close relationship of 99.1\% which was anticipated beforehand. The contrary holds true in case two elements are assessed opposite on all constructs. A relative distance of $100 \%$ we be the result. The distance between a "a negative company" and "the ideal company" is 74.5 , representing a degree of association of $25.5 \%$. For testing hypothesis and to compile an overview which identified clusters coincide with Herzberg's theory the degree of association was separated into 3 categories:

\begin{tabular}{|c|c|}
\hline Type of factor & Degree of association \\
\hline Motivator & $75-100 \%$ \\
\hline Hygiene & $50-75 \%$ \\
\hline Dissatisfaction / Demotivation & $25-50 \%$ \\
\hline
\end{tabular}

Table 2: Categories of degree of association

Orientation is provided in this three-dimensional grid by the two element poles "A negative company" and "The ideal company". The distances (of a maximum of 100) to these two poles implies how good or adverse a subject is assessed. For the creation of clusters, the software rep:grid created a first proposal set of clusters in dependence of the closeness of constructs. This first set included all 782 constructs. The preview cluster set based on mathematical figures was examined semantically regarding their coherence with motivational theories. That way all constructs were semantically evaluated and assigned to one of the initial or a new cluster. This resulted in 34 clusters. The software rep:grip allocated the centric position of these cluster by GPA.

\section{Results and Discussion}

The personal constructs elicited in this research were semantically summarized into 34 clusters of which each contained between 13 and 34 constructs. These clusters in turn can be summed up into 5 main topics. 71 personal constructs are classified as unassigned as they did not fit into the below listed scheme. 


\begin{tabular}{|c|c|c|c|c|c|c|c|}
\hline & \multirow[b]{2}{*}{ Topic related clusters } & \multicolumn{2}{|c|}{ Constructs } & \multicolumn{4}{|c|}{ degree of correlation } \\
\hline & & $N$ & in $\%$ & $\begin{array}{c}\text { A highly } \\
\text { motivated } \\
\text { person }\end{array}$ & $\begin{array}{l}\text { The ideal } \\
\text { company }\end{array}$ & $\begin{array}{c}\text { The } \\
\text { company } \\
\text { today }\end{array}$ & $\begin{array}{c}\text { A negative } \\
\text { company }\end{array}$ \\
\hline \multirow{5}{*}{ 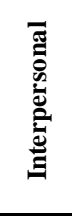 } & Self motivation through team spirit & 27 & $3.5 \%$ & 0.881 & 0.888 & 0.510 & 0.329 \\
\hline & Good relationsship with peers & 19 & $2.4 \%$ & 0.905 & 0.920 & 0.482 & 0.317 \\
\hline & Egocentricity, Silo-mentality & 26 & $3.3 \%$ & 0.311 & 0.303 & 0.590 & 0.921 \\
\hline & Impersonal togetherness / Blasphemy & 30 & $3.8 \%$ & 0.351 & 0.342 & 0.657 & 0.901 \\
\hline & Efficient and positive communication & 16 & $2.0 \%$ & 0.875 & 0.858 & 0.543 & 0.386 \\
\hline \multirow{6}{*}{ 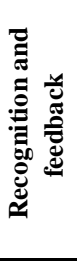 } & Responsility is not taken, no recognition & 15 & $1.9 \%$ & 0.328 & 0.316 & 0.683 & 0.916 \\
\hline & Performance orientation & 16 & $2.0 \%$ & 0.805 & 0.853 & 0.525 & 0.417 \\
\hline & Honest, critical feedback & 15 & $1.9 \%$ & 0.906 & 0.920 & 0.424 & 0.310 \\
\hline & Error prevention & 23 & $2.9 \%$ & 0.398 & 0.387 & 0.701 & 0.857 \\
\hline & Organizational Silence & 15 & $1.9 \%$ & 0.339 & 0.325 & 0.704 & 0.900 \\
\hline & Open error culture & 21 & $2.7 \%$ & 0.830 & 0.852 & 0.498 & 0.390 \\
\hline \multirow{4}{*}{ 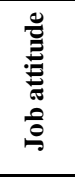 } & Employee development \& growth & 29 & $3.7 \%$ & 0.854 & 0.850 & 0.531 & 0.405 \\
\hline & Intrinsic passion for the job & 27 & $3.5 \%$ & 0.917 & 0.866 & 0.510 & 0.330 \\
\hline & Work-to-rule & 28 & $3.6 \%$ & 0.361 & 0.359 & 0.579 & 0.841 \\
\hline & Stay in the comfort zone & 18 & $2.3 \%$ & 0.356 & 0.340 & 0.783 & 0.817 \\
\hline \multirow{8}{*}{ 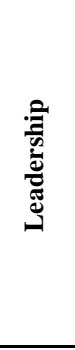 } & Autocratic Leadership & 15 & $1.9 \%$ & 0.374 & 0.364 & 0.603 & 0.870 \\
\hline & Cooperative Leadership & 19 & $2.4 \%$ & 0.910 & 0.895 & 0.508 & 0.324 \\
\hline & Clearly defined strategy and goals & 34 & $4.3 \%$ & 0.903 & 0.891 & 0.470 & 0.349 \\
\hline & Controlling supervisors & 14 & $1.8 \%$ & 0.496 & 0.467 & 0.862 & 0.677 \\
\hline & Unclear instructions, missing strategy & 30 & $3.8 \%$ & 0.318 & 0.310 & 0.630 & 0.920 \\
\hline & Clear \& dis tributed responsibilities & 20 & $2.6 \%$ & 0.876 & 0.883 & 0.495 & 0.371 \\
\hline & Involement is missing & 21 & $2.7 \%$ & 0.382 & 0.368 & 0.664 & 0.886 \\
\hline & Inclusion and involvement & 15 & $1.9 \%$ & 0.837 & 0.849 & 0.503 & 0.290 \\
\hline \multirow{12}{*}{ 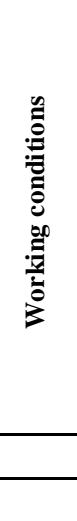 } & Exhaustion, overtime and demotivation & 26 & $3.3 \%$ & 0.368 & 0.357 & 0.675 & 0.890 \\
\hline & Wasteful processes & 31 & $4.0 \%$ & 0.338 & 0.327 & 0.661 & 0.913 \\
\hline & Agile working attitude / open-mindedness & 23 & $2.9 \%$ & 0.851 & 0.848 & 0.532 & 0.407 \\
\hline & Efficient working conditions & 32 & $4.1 \%$ & 0.918 & 0.879 & 0.511 & 0.345 \\
\hline & Sluggishness in change & 19 & $2.4 \%$ & 0.331 & 0.318 & 0.709 & 0.890 \\
\hline & Continuous optimization & 21 & $2.7 \%$ & 0.860 & 0.889 & 0.447 & 0.343 \\
\hline & Healthy working conditions & 15 & $1.9 \%$ & 0.739 & 0.754 & 0.562 & 0.475 \\
\hline & Innovative work environment & 13 & $1.7 \%$ & 0.871 & 0.853 & 0.544 & 0.393 \\
\hline & Salary and security & 19 & $2.4 \%$ & 0.752 & 0.745 & 0.669 & 0.480 \\
\hline & Pure profit orientation & 19 & $2.4 \%$ & 0.445 & 0.429 & 0.702 & 0.822 \\
\hline & (Unassigned) & 71 & $9.1 \%$ & 0.718 & 0.713 & 0.641 & 0.536 \\
\hline & Total & 782 & & & & & \\
\hline
\end{tabular}

Table 3: Construct clusters and their degree of correlation with elements

The central element for this research is "a highly motivated person". To test hypothesis one, the prevalence of Herzberg's two factor theory the construct clusters are equated to the motivation or hygiene factors. Accordingly, the first analysis determines which clusters have the highest correlation with the element a highly motivated person. The data set reveals that 
intrinsic passion for the job and efficient working conditions (both 92\%) or according to Herzberg's theory "the work itself" is the strongest motivator. This means that a challenging, stimulating, and well-organized working environment is a main driver to motivate employees in a VUCA environment. The clusters with the second highest degree of correlation are a cooperative leadership and honest, critical feedback. This does not fully match with Herzberg's two-factor theory as it associates most with "Quality of supervision". It seems the factor moved from hygiene to motivation which already confirms hypothesis two. A different approach to leadership is required and has a strong impact on motivation. Thirdly the data set highlights good relationship with peers (91\%) as a main cluster for a highly motivated person. This may conclude that inter-personal relationships are still prevalent but evolved into a motivational factor. Salary and security correlates $75 \%$ with a highly motivated person and ideal company (75\%) which highlights it still as a hygiene factor. Herzberg's hygiene factor company policy can be aligned to healthy working conditions $(74 \%)$.

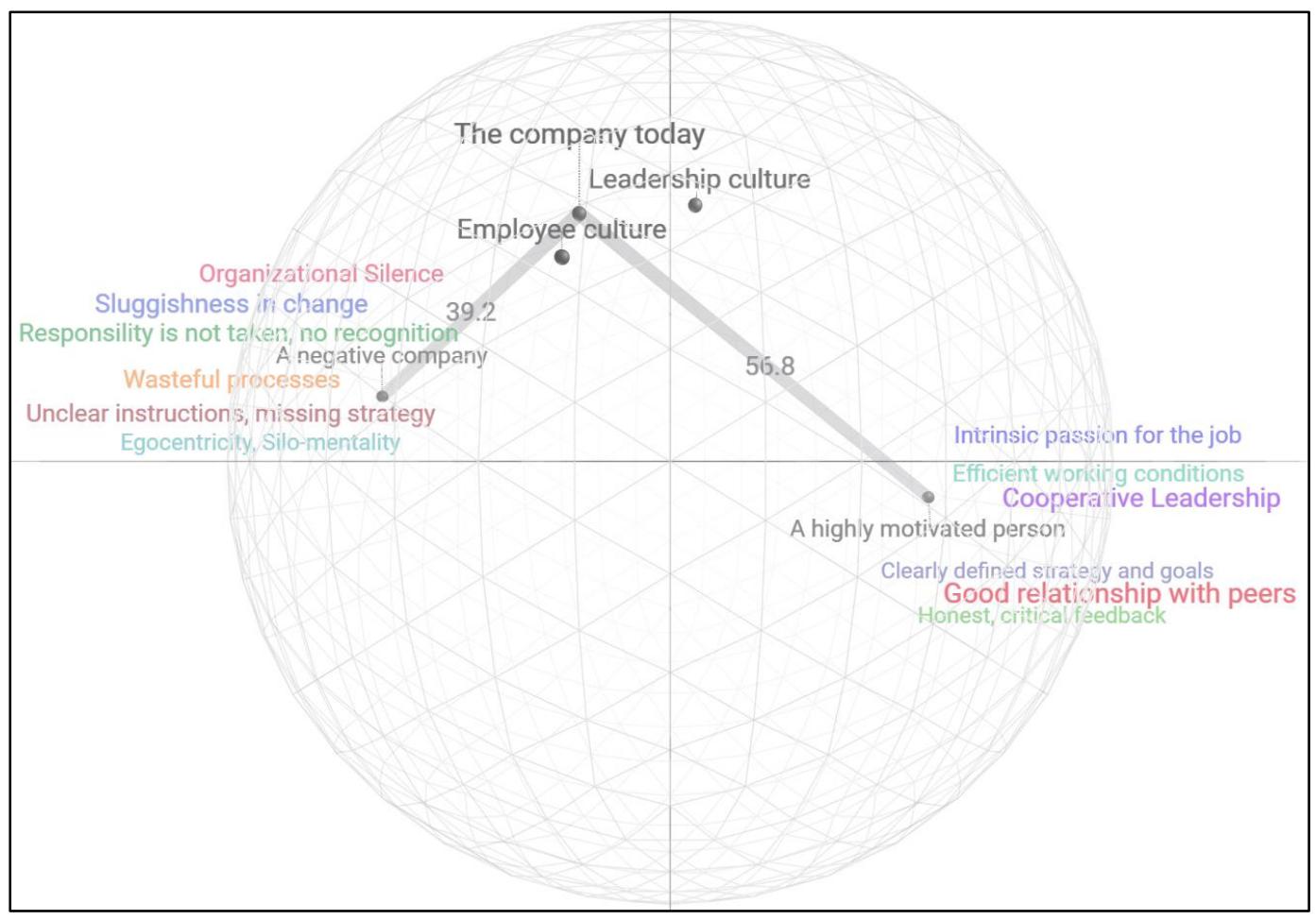

Figure 1: Visualization of construct clusters and their correlation with elements

In turn we need to investigate what has the least correlation with a highly motivated person so might rather be demotivating or dissatisfying (25 - 50\%). Two clusters centre around the efficiency of the working conditions. Egocentricity, Silo-mentality (31\%) and Wasteful processes (34\%) are clusters that describe how employees and leaders can carry out their work. If efficiency is not given this may lead to demotivation. These two constructs are exactly the contrary to the motivating cluster efficient working conditions. Furthermore, if responsibility is not taken, no recognition (33\%) is given this leads to demotivation or dissatisfaction according to the data set. Already Herzberg described responsibility and 
recognition as a motivating factor in his theory, so this is confirmed by this study. The cluster can be identified as contrarian to cooperative leadership. Organizational silence (34\%) stands for employees not giving critical feedback or withholding their ideas. Hence it can be paired to Honest and critical feedback which was identified on the other hand as being a motivator. If ideas and suggestions are withheld it indicates an interrelation with the cluster Sluggishness in change (33\%) which is identified by this research as another cluster that is associated contrarious with a motivated person. Advancement and personal growth are the motivating factors Herzberg defined in his theory which is closest to the cluster names. Critical selfreflection and feedback are main drivers for personal growth. Finally, unclear instructions, missing strategy (32\%) are another demotivating factor that confirms clearly defined strategy and goals as a motivating motive. Conclusive in today's working environment employees are motivated by a strategy that is defined and communicated. The following table summarizes the clusters that were identified in accordance with the classification defined in the chapter materials and methods:

\begin{tabular}{|lcc|c|ll|}
\hline & Constructs & degree of correlation & \multicolumn{2}{|c|}{ Factors } \\
\hline Topic related clusters & $\mathbf{N}$ & in \% & $\begin{array}{c}\text { A highly motivated } \\
\text { person }\end{array}$ & findings & $\begin{array}{l}\text { Herzberg's } \\
\text { theory }\end{array}$ \\
\hline Self motivation through team spirit & $\mathbf{2 7}$ & $\mathbf{3 . 5 \%}$ & $\mathbf{0 . 8 8 1}$ & motivator & hygiene \\
Good relationship with peers & $\mathbf{1 9}$ & $\mathbf{2 . 4 \%}$ & $\mathbf{0 . 9 0 5}$ & motivator & hygiene \\
Efficient and positive communication & $\mathbf{1 6}$ & $\mathbf{2 . 0 \%}$ & $\mathbf{0 . 8 7 5}$ & motivator & hygiene \\
Performance orientation & 16 & $2.0 \%$ & 0.805 & motivator & motivator \\
Honest, critical feedback & $\mathbf{1 5}$ & $\mathbf{1 . 9 \%}$ & $\mathbf{0 . 9 0 6}$ & motivator & - \\
Open error culture & $\mathbf{2 1}$ & $\mathbf{2 . 7 \%}$ & $\mathbf{0 . 8 3 0}$ & motivator & - \\
Employee development \& growth & 29 & $3.7 \%$ & 0.854 & motivator & motivator \\
Intrinsic passion for the job & 27 & $3.5 \%$ & 0.917 & motivator & motivator \\
Cooperative Leadership & $\mathbf{1 9}$ & $\mathbf{2 . 4 \%}$ & $\mathbf{0 . 9 1 0}$ & motivator & hygiene \\
Clearly defined strategy and goals & 34 & $4.3 \%$ & 0.903 & motivator & motivator \\
Controlling supervisors & 14 & $1.8 \%$ & 0.496 & hygiene & hygiene \\
Clear \& distributed responsibilities & 20 & $2.6 \%$ & 0.876 & motivator & motivator \\
Inclusion and involvement & 15 & $1.9 \%$ & 0.837 & motivator & motivator \\
Agile working attitude / open-mindedness & $\mathbf{2 3}$ & $\mathbf{2 . 9 \%}$ & $\mathbf{0 . 8 5 1}$ & motivator & - \\
Efficient working conditions & 32 & $4.1 \%$ & 0.918 & motivator & motivator \\
Continuous optimization & 21 & $2.7 \%$ & 0.860 & motivator & motivator \\
Healthy working conditions & 15 & $1.9 \%$ & 0.739 & hygiene & hygiene \\
Innovative work environment & 13 & $1.7 \%$ & 0.871 & motivator & motivator \\
Salary and security & 19 & $2.4 \%$ & 0.752 & hygiene & hygiene \\
\hline
\end{tabular}

Table 4: Classification of construct clusters in motivation and hygiene factors

This classification table in combination with the defined categories facilitates a test of hypothesis three: $\mathrm{H}_{3}$ : Agile working methods can by identified as a hygiene factor. The cluster "agile working attitude / open-mindedness" is associated to a degree of $85 \%$ with the element "a highly motivated person". Conclusively agile working methods function as a motivator 
rather than only being a hygiene factor in today's working environment. This can be explained by the changes that occurred with respect to the economic environment since Herzberg compiled his research. The effects on motivation through more agile working methods are scientifically proven as empowerment, flat hierarchies and interdisciplinary teams diversify jobs while promoting and efficient and proactive internal communication. Interesting is that being capable to manage a volatile, uncertain, and complex world serves even as a motivator for employees and leaders. Further research on this point could verify or falsify this finding. Summarizing though hypothesis three was not confirmed.

The following figure visualizes the clusters that were aligned to the factors identified by Herzberg. The closer they are to the element "a highly motived person" the more likely they are to be a motivational factor.

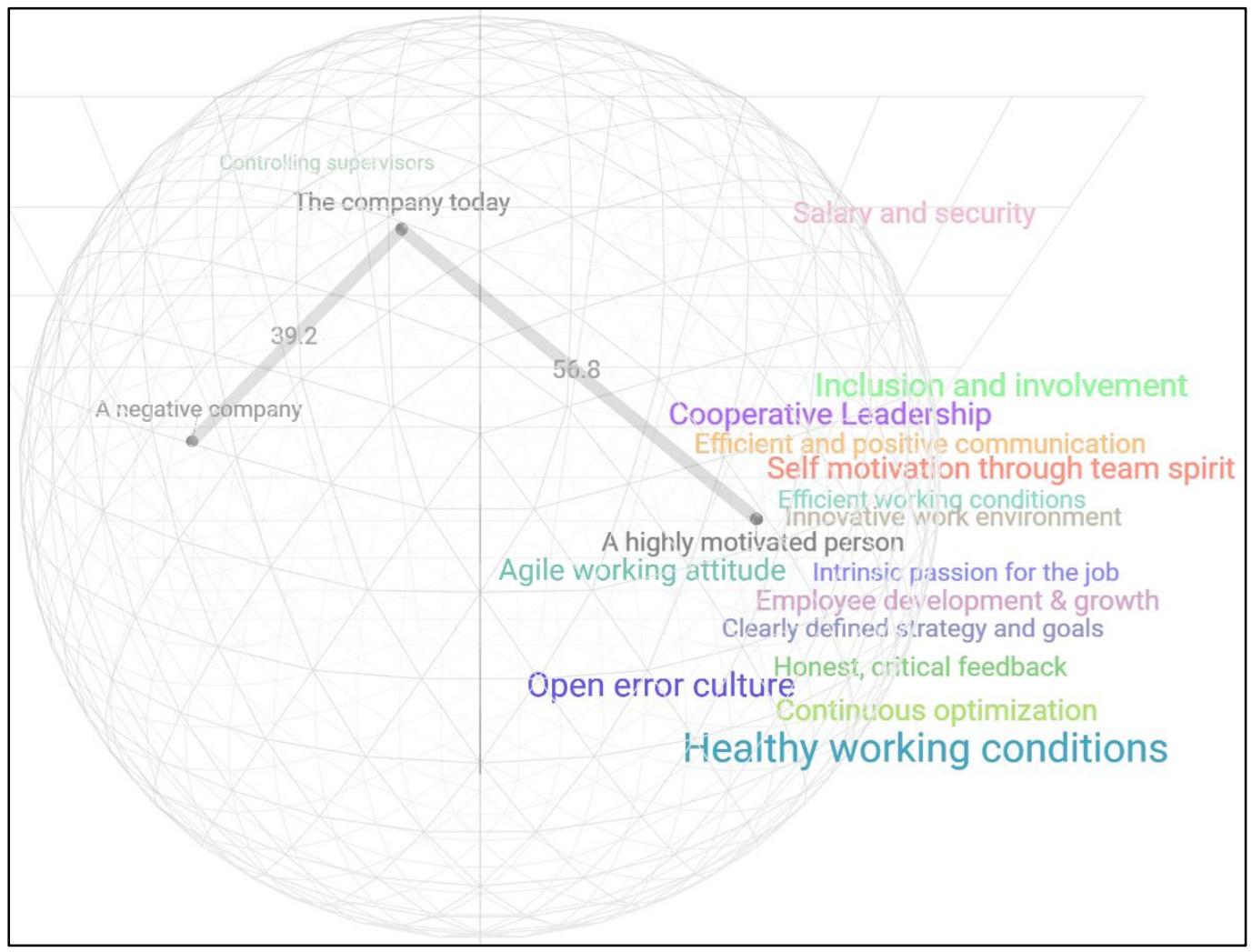

Figure 2: Construct clusters associated with a highly motivated person (element)

12 of 19 clusters confirm Herzberg's motivation-hygiene theory for today's working environment even the economic circumstances have changed considerably. Seven clusters revealed by this repertory grid study are either not part of Herzberg's theory or the findings of this study contradict to his theory. The first three clusters of table four relate to the interpersonal relationship of employees and leaders. According to Herzberg's theory these are hygiene factors, their association with motivation indicate them as motivational factors. As discussed by Myers und Sadaghiani (2010) this is due to the changed values and ethics of 
generation Y. Work and relationship has become more important while salary and achievement are not as relevant anymore.

The second main finding is that honest, critical feedback and an open error culture serve as motivational factors. Our economy has become less predictable and changes are occurring faster than in the century Kelly wrote his theory. Therefore, an open-minded approach towards committing errors in combination with an honest and critical feedback is needed to cope with the challenges in a volatile and complex economic environment. These factors support advancement and personal growth but were not explicitly listed in Herzberg's theory. In the 1960's the leadership approach was minted more autocratic. Managers were the former employees with most knowledge capable to plan the future. Error prevention was a prime aim whilst committing and communicate mistakes was rather seen as a weakness. This leadership and error management approach changed into a mindset expectation towards Cooperative leadership (91\% association with high motivation) and open error culture (83\%). Herzberg named his hygiene factor "quality of supervision" which based on a contrary perception of supervision than today's cooperative leadership approach. Summarizing hypothesis four can be confirmed, teamwork and feedback were identified as motivational factors.

\section{Conclusion}

Despite the changes in leadership and management, the economic environment and the type of workforce, Herzberg's theory is still reproducible to a wide extend in contemporary work environment. The data set supports the assumption that feedback and an open error culture must be considered as motivational factors due to an economic surrounding described by the term VUCA (Bennett und Lemoine 2014). Additionally, this is supported by another motivator named agile working methods. Quality of supervision was included in the 2-factor theory as a hygiene factors, but this study suggests a renaming to Cooperative Leadership which conditions a shift to being a motivator. Finally, teamwork, efficient communication and good interpersonal relationship were identified as an additional motivator while Herzberg considered these as hygiene factors. The literature review did not indicate this shift nevertheless it is an interesting finding that would need testing in an embraced study. Auxiliary the research shows that repertory grid structured interviews based on Kelly's theory of personal constructs are a suitable way to investigate the two-factor theory. Further research based on this adapted hygiene-motivation theory is needed to test the theory on its withstanding in contemporary working environment. The limitation of the study is the data set as it only reflects one organization with 61 qualitative interviews as a combination of employees and all leaders. Nevertheless, it can create a first evidence on how Herzberg's theory could be adapted to today's economic environment and changed labour market. The author suggests further quantitative, specific research to be conducted based on the finding of this study. This would refine the current scientific status and could produce valuable practical advice on how organizations can cope with the current economic challenges while motivating, retain and satisfying their workforce.

\section{References}

[1] Arnold, Josh A.; Arad, Sharon; Rhoades, Jonathan A.; Drasgow, Fritz (2000): The empowering leadership questionnaire: the construction and validation of a new scale for measuring leader behaviors. In: J. Organiz. Behav. 21 (3), S. 249-269. DOI: 10.1002/(SICI)1099-1379(200005)21:3<249::AID-JOB10>3.0.C0;2-\#. 
[2] Baran, Benjamin E.; Woznyj, Haley M. (2020): Managing VUCA: The human dynamics of agility. In: Organizational Dynamics, S. 100787. DOI: 10.1016/j.orgdyn.2020.100787.

[3] Bennett, Nathan; Lemoine, G. James (2014): What a difference a word makes: Understanding threats to performance in a VUCA world. In: Business Horizons 57 (3), S. 311-317. DOI: 10.1016/j.bushor.2014.01.001.

[4] Bourne, Dorota; Jankowicz, Devi A. (2018): The Repertory Grid Technique. In: Malgorzata Ciesielska und Dariusz Jemielniak (Hg.): Qualitative Methodologies in Organization Studies, Bd. 6. Cham: Springer International Publishing, S. 127-149.

[5] Brenner, Vincent C.; Carmack, Claude W.; Weinstein, Mark G. (1971): An Empirical Test of the Motivation-Hygiene Theory. In: Journal of Accounting Research 9 (2), S. 359. DOI: $10.2307 / 2489939$.

[6] Cassell, Catherine; Close, Paul; Duberley, Joanne; Johnson, Phil (2000): Surfacing embedded assumptions: Using repertory grid methodology to facilitate organizational change. In: European Journal of Work and Organizational Psychology 9 (4), S. 561-573. DOI: 10.1080/13594320050203139.

[7] Caston, R. J., \& Braito, R. (1985): A specification issue in job satisfaction research. What happens to job satisfaction models when workers place high value on increasing their satisfaction? In: Sociological Perspectives 28 (2), S. 175-197.

[8] Chen, Gilad; Kirkman, Bradley L.; Kanfer, Ruth; Allen, Don; Rosen, Benson (2007): A multilevel study of leadership, empowerment, and performance in teams. In: Journal of Applied Psychology 92 (2), S. 331-346. DOI: 10.1037/0021-9010.92.2.331.

[9] Costanza, David P.; Badger, Jessica M.; Fraser, Rebecca L.; Severt, Jamie B.; Gade, Paul A. (2012): Generational Differences in Work-Related Attitudes: A Meta-analysis. In: Journal of business and psychology 27 (4), S. 375-394. DOI: 10.1007/s10869-0129259-4.

[10] Easterby-Smith, Mark; Thorpe, Richard; Holman, David (1996): Using repertory grids in management. In: Jnl Euro Industrial Training 20 (3), S. 3-30. DOI: 10.1108/03090599610114138.

[11] Fransella, Fay (Hg.) (2004): International handbook of personal construct psychology. Chichester u.a: Wiley.

[12] Fromm, Martin (2004): Introduction to the Repertory Grid Interview. s.l.: Waxmann Verlag. Online verfügbar unter https://contentselect.com/portal/media/cover_image/54f81ebe-cda8-4bff-9aca71e0b0dd2d03/500.

[13] Gardner, G. (1977): Is there a valid test of Herzberg's two-factor theory? In: Journal of Occupational Psychology 50 (3), S. 197-204. DOI: 10.1111/j.20448325.1977.tb00375.x.

[14] Gower, John (1975): Generalized Procrustes analysis. In: Psychometrika 45(1):3-24.

[15] Grice, James W.; Assad, Kimberly K. (2009): Generalized Procrustes Analysis: A Tool for Exploring Aggregates and Persons. In: AMR 13 (1), S. 93. DOI: 10.22329/amr.v13i1.2836.

[16] Hackman, J. R., \& Oldham, G. R. (1976): Motivation through the design of work. Test of a theory. In: Organizational Behavior \& Human Performance (16(2)), S. 250-279.

[17] Hauser, Mirjam; Jonas, Klaus; Riemann, Rainer (2011): Measuring salient food attitudes and food-related values. An elaborated, conflicting and interdependent system. In: Appetite 57 (2), S. 329-338. DOI: 10.1016/j.appet.2011.05.322. 
[18] Herzberg, Frederick (1966): Work and the nature of man. New York: Crowell.

[19] Herzberg, Frederick; Mausner, Bernard; Snyderman, Barbara B. (1959): The motivation to work. 2. ed. New York, London: Wiley; Chapman \& Hall.

[20] Kelly, George (2002): The Psychology of Personal Constructs: Routledge.

[21] Kelly, George A. (1955): The Psychology of Personal Constructs. Norton, New York.

[22] King, Nathan (1970): Clarification and evaluation of the two-factor theory of job satisfaction. In: Psychological Bulletin 74 (1), S. 18-31. DOI: 10.1037/h0029444.

[23] Knoop, Robert (1994): Work Values and Job Satisfaction. In: The Journal of Psychology 128 (6), S. 683-690. DOI: 10.1080/00223980.1994.9921297.

[24] Lawler, Edward J. (1969): Job Design and Employee Motivation. In: Personnel Psychology 22 (4), S. 426-435. DOI: 10.1111/j.1744-6570.1969.tb00343.x.

[25] Locke, Edwin A.; Latham, Gary P. (1990): Work Motivation and Satisfaction: Light at the End of the Tunnel. In: Psychol Sci 1 (4), S. 240-246. DOI: 10.1111/j.14679280.1990.tb00207.x.

[26] Lohaus, Arnold (1983): Möglichkeiten individuumzentrierter Datenerhebung. Zugl.: Münster (Westfalen), Univ., Diss. Münster: Aschendorff (Arbeiten zur sozialwissenschaftlichen Psychologie, 12).

[27] Maidani, Ebrahim A. (1991): Comparative Study of Herzberg's Two-Factor Theory of Job Satisfaction among Public and Private Sectors. In: Public Personnel Management 20 (4), S. 441-448. DOI: 10.1177/009102609102000405.

[28] Mak, Athena H.N.; Lumbers, Margaret; Eves, Anita; Chang, Richard C.Y. (2013): An application of the repertory grid method and generalised Procrustes analysis to investigate the motivational factors of tourist food consumption. In: International Journal of Hospitality Management 35, S. 327-338. DOI: 10.1016/j.ijhm.2013.07.007.

[29] Myers, Karen K.; Sadaghiani, Kamyab (2010): Millennials in the Workplace: A Communication Perspective on Millennials' Organizational Relationships and Performance. In: Journal of business and psychology 25 (2), S. 225-238. DOI: 10.1007/s10869-010-9172-7.

[30] Orpen, Christopher (1979): The Effects of Job Enrichment on Employee Satisfaction, Motivation, Involvement, and Performance. A Field Experiment. In: Human Relations (32(3)), S. 189-217.

[31] Robertson, Adrian (2004): Making Sense of the 'Group Mind'. In: Fay Fransella (Hg.): International handbook of personal construct psychology. Chichester u.a: Wiley, S. 339-348.

[32] Sachau, Daniel A. (2007): Resurrecting the Motivation-Hygiene Theory: Herzberg and the Positive Psychology Movement. In: Human Resource Development Review 6 (4), S. 377-393. DOI: $10.1177 / 1534484307307546$.

[33] Scheer, Jörn W.; Catina, Ana (Hg.) (1993): Einführung in die Repertory Grid-Technik. Bd. 2. Klinische Forschung und Praxis. 1. Aufl. Bern, Göttingen, Toronto, Seattle: Huber.

[34] Smerek, Ryan E.; Peterson, Marvin (2006): Examining Herzberg's Theory: Improving Job Satisfaction among Non-academic Employees at a University. In: Res High Educ 48 (2), S. 229-250. DOI: 10.1007/s11162-006-9042-3.

[35] Steers, Richard M.; Mowday, Richard T.; Shapiro, Debra L. (2004): The Future of Work Motivation Theory. In: AMR 29 (3), S. 379-387. DOI: 10.5465/amr.2004.13670978. 
[36] Stewart, Jeanine S.; Oliver, Elizabeth Goad; Cravens, Karen S.; Oishi, Shigehiro (2017): Managing millennials: Embracing generational differences. In: Business Horizons 60 (1), S. 45-54. DOI: 10.1016/j.bushor.2016.08.011.

[37] Wall, Toby D.; Stephenson, Geoffrey M. (1970): Herzberg's two-factor theory of job attitudes: a critical evaluation and some fresh evidence. In: Industrial Relations J 1 (3), S. 41-65. DOI: 10.1111/j.1468-2338.1970.tb00262.x.

[38] Wong, Melissa; Gardiner, Elliroma; Lang, Whitney; Coulon, Leah (2008): Generational differences in personality and motivation. In: Journal of Managerial Psych 23 (8), S. 878-890. DOI: 10.1108/02683940810904376.

[39] Wright, Robert P.; Lam, Simon S. K. (2002): COMPARING APPLES WITH APPLES: THE IMPORTANCE OF ELEMENT WORDING IN GRID APPLICATIONS. In: Journal of Constructivist Psychology 15 (2), S. 109-119. DOI: 10.1080/10720530252808692. 